\title{
Monoclonal antibodies to human factor VII: production of immunodepleted plasma for VII:C assays
}

\author{
T TAKASE, E G D TUddenham, S Chand, alison h Goodall From the Haemophilia Centre and \\ Haemostasis Unit, Academic Department of Haematology, Royal Free Hospital and School of Medicine, \\ London
}

SUMmARY A high affinity monoclonal antibody to factor VII (RFF-VII/1), coupled to sepharose, was used to immunodeplete factor VII from normal plasma. The plasma could be used as a substrate in a one stage coagulation assay and performed as well as, or better than, commercially available factor VII deficient plasma or plasma from congenitally deficient factor VII patients. Plasma from normal donors $(n=20)$, patients with liver disease $(n=20)$, and patients receiving warfarin $(n=20)$, or congenitally factor VII deficient patients $(n=7)$ was assayed for VII:C concentration in a one stage coagulation assay. The concentration of VII:C detected with the immunodepleted plasma substrate was comparable in all cases with that seen with a commercially available substrate $(r=0.95)$.

The detection of factor VII coagulation activity (VII:C) relies on the availability of plasma from patients severely deficient in factor VII or on the use of artificially produced human, ${ }^{1}$ or bovine ${ }^{23}$ deficient plasma. Factor VII deficiency is, however, an extremely rare disorder ${ }^{4}$ and the availability of such deficient plasma is therefore limited.

The detection of VII:C is not only of importance in patients with bleeding disorders but also in those with suspected cardiovascular disease. The activities of VII:C and VII:Ag are thought to be good prognostic indicators for myocardial infarction. ${ }^{5}$ Monoclonal antibodies to factor VII have been raised ${ }^{67}$ and shown to be useful in depleting factor VII from normal plasma. $^{7}$

In this paper we show the use of one monoclonal antibody (RFF-VII/1) to immunodeplete factor VII from large volumes of normal human plasma and the use of this substrate for detecting VII:C in plasma from healthy subjects and from patients with a variety of disorders.

\section{Material and methods}

Blood (about 1 unit) was collected from normal healthy volunteers and immediately separated. Plasma was tested for hepatitis B surface antigen (HBsAg) ${ }^{8}$ and for human immunodeficiency virus (HIV) (Wellcozyme anti-HTLV III test, Wellcome Laboratories) before pooling and using immediately.

Accepted for publication 18 August 1987
Blood samples from 20 normal subjects, 20 patients with liver disease, 20 patiens treated with warfarin, and seven patients with congenital factor VII deficiency were collected and stored as described in the previous paper. ${ }^{9}$

VII:C was assayed by a one stage method using human thromboplastin and calcium. The substrate for the assays was either commercial factor VII deficient substrate (Boehringer, Mannheim, or Sigma), plasma from a congenital factor VII deficient patient, or immunodepleted plasma prepared as described below.

IMMUNODEPLETED PLASMA

The production and characterisation of RFF-VII/1 has been described in the preceding paper.' The monoclonal antibody column was prepared by coupling $6 \mathrm{mg}$ of RFF-VII/ 1 to $1 \mathrm{ml}$ of cyanogen bromide activated sepharose 4B (Pharmacia Fine Chemicals, Uppsala, Sweden). Normal plasma obtained from healthy donors was applied to this column at $4^{\circ} \mathrm{C}$ at a flow rate of $6 \mathrm{ml} /$ hour. The flow through was monitored for residual VII:C and fractions containing less than $0.3 \mathrm{U} / \mathrm{dl}$ were pooled.

\section{PURIFICATION OF FACTOR VII USING}

MONOCLONAL COLUMN

Human acid citrated dextrose (ACD) plasma was treated by a combination of barium citrate adsorption, 25-70\% saturated ammonium sulphate (SAS) precipitation, and DEAE-sepharose CL6B column chromatography. Details of this procedure have been described previously. ${ }^{10}$ Fractions rich in factor VII from the DEAE-sepharose CL6B column were 
Table 1 Residual concentrations of coagulation factors in $R F F-V I I / 1$ depleted plasma

\begin{tabular}{lcc}
\hline Factor & Before $(U /$ dl $)$ & After $(U /$ dl $)$ \\
\hline II & 145 & 145 \\
V & 100 & 100 \\
VII:C & 110 & $<0 \cdot 3$ \\
VII:Ag & 98 & $<0 \cdot 05$ \\
VIII & 94 & 94 \\
IX & 130 & 102 \\
X & 108 & 108 \\
XI & 96 & 76 \\
XII & 210 & 180 \\
Fibrinogen & $2 \cdot 4 \mathrm{~g} / 1$ & $2 \cdot 4 \mathrm{~g} / 1$ \\
\hline
\end{tabular}

applied to an RFF-VII/1-sepharose column $(1 \times 1 \cdot 2$ $\mathrm{cm})$ that had been equilibrated with $0.02 \mathrm{M}$ Trishydrochloric acid buffer, containing $0 \cdot 25 \mathrm{M}$ sodium chloride, $0.02 \mathrm{M}$ benzamidine, and $0.1 \mathrm{mM}$ diisofluorophosphate (pH 7.4). After washing with buffer, bound protein was eluted with the same buffer, containing $2 \mathrm{M} \mathrm{NaSCN}$, then immediately dialysed against $0.01 \mathrm{M}$ sodium phosphate buffer $(\mathrm{pH} \mathrm{7.4)}$ at $4^{\circ} \mathrm{C}$, overnight. After dialysis purified factor VII was aliquoted and stored at $-70^{\circ} \mathrm{C}$ until use.

Gradient polyacrylamide gels $(5-17.5 \%)$ were prepared by the method of Laemmli. ${ }^{11}$ Gradients were formed in the same plate from a $5 \%$ acrylamide chamber and a $17 \cdot 5 \%$ acrylamide $/ 10 \%$ glycerol chamber, using an LKB gradient mixer.

Electrophoresis was performed at 50 volts per plate. The gels were stained for protein with Coomassie brilliant blue. This procedure has been described in greater detail in a previous paper. ${ }^{12}$

\section{Results}

CHARACTERISTICS OF IMMUNODEPLETED PLASMA Using a $1 \mathrm{ml}$ column of RFF-VII/1, about $200 \mathrm{ml}$ of

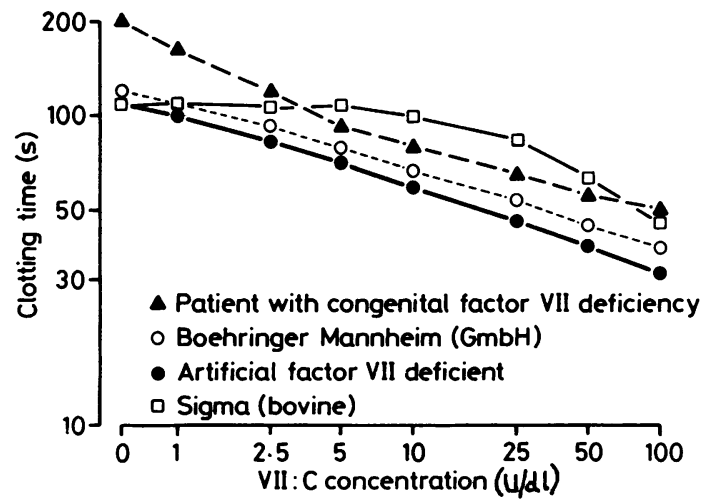

Fig 1 Assay curves for VII:C in normal pooled plasma using four different substrates. Dilutions of normal pooled plasma (between 1/10 and 1/1000) were assayed in a one stage VII:C assay using human thromboplastin and calcium.

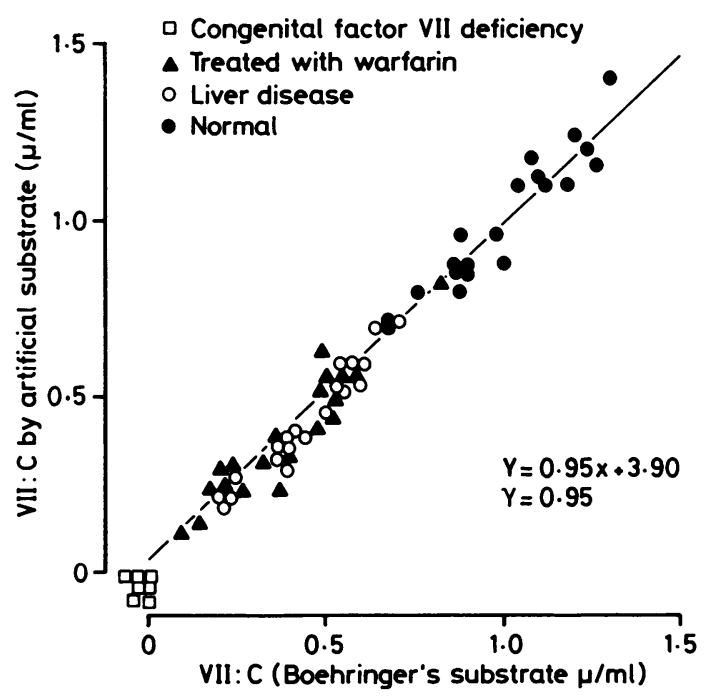

Fig 2 VII:C activity in plasma. Correlation of VII:C concentrations obtained with the immunodepleted plasma ( $y$ axis) or a commercial (Boehringer) substrate ( $x$ axis) for 20 normal plasmas ( ), 20 patients with liver disease (O), 20 treated with warfarin $(\mathbf{\Delta})$ and seven with congenital factor VII deficiency ( $\square$ ).

immunodepleted plasma (VII:C $<0.3 \mathrm{U} / \mathrm{dl}$ ) was made from normal pooled plasma. Measurement of VII:Ag by radioimmunoassay ${ }^{10}$ confirmed that the removal of factor VII was complete. The concentrations of all other coagulation factors remained unchanged (table 1).

Standard curves were perfomed using as substrate either this immunodepleted plasma or two kinds of commercial factor VII deficient plasma or factor VII deficient plasma obtained from a congenitally factor VII deficient patient. The immunodepleted plasma gave the best standard curve, comparable with the best commercially available deficient plasma (Boehringer), particularly at concentrations of VII:C below $2.5 \mathrm{U} / \mathrm{dl}$ (fig 1).

VII:C was measured in plasma obtained from 20 normal subjects, 20 patients with liver disease, 20 patients treated with warfarin, and seven patients with severe congenital factor VII deficiency.

In normal plasma VII:C concentrations were between 70 and $130 \mathrm{U} / \mathrm{dl}$ (mean (SD) 100 (18)). In the plasma of patients with liver disease, those treated with warfarin, and those with congenital factor VII deficiency, the concentrations of VII:C were between 20 and $72 \mathrm{U} / \mathrm{dl}(44(15))$, between 10 and $84 \mathrm{U} / \mathrm{dl}$ (40(18)), and below $1 \mathrm{U} / \mathrm{dl}$, respectively. Correlations of the concentrations of VII:C obtained in the samples with the immunodepleted plasma or with commercial substrate were very similar $(r=0.95)$ (fig 2$)$. 
Table 2 Purification of factor VII from human plasma using monoclonal antibody column

The same plasma samples had been analysed for VII:Ag by radioimmunoassay or by immunoradio metric assay using monoclonal antibodies, as previously described. ' Concentrations of VII:C, measured with the immunodepleted substrate, correlated well $(r=0.95)$ with those of VII:Ag measured in the monoclonal antibody-immunoradio metric assay (fig 3) for normal subjects and for patients. The patients with severe congenital factor VII deficiency had variable to low concentrations of VII:Ag, as discussed previously. ${ }^{9}$

PURIFICATION OF FACTOR VII BY MONOCLONAL COLUMN CHROMATOGRAPHY

Factor VII was purified from fresh frozen human plasma by absorption on the RFF-VII/1 column, following a combination of barium chloride adsorption, precipitation with saturated ammonium sulphate, and DEAE-sepharose CL6B column

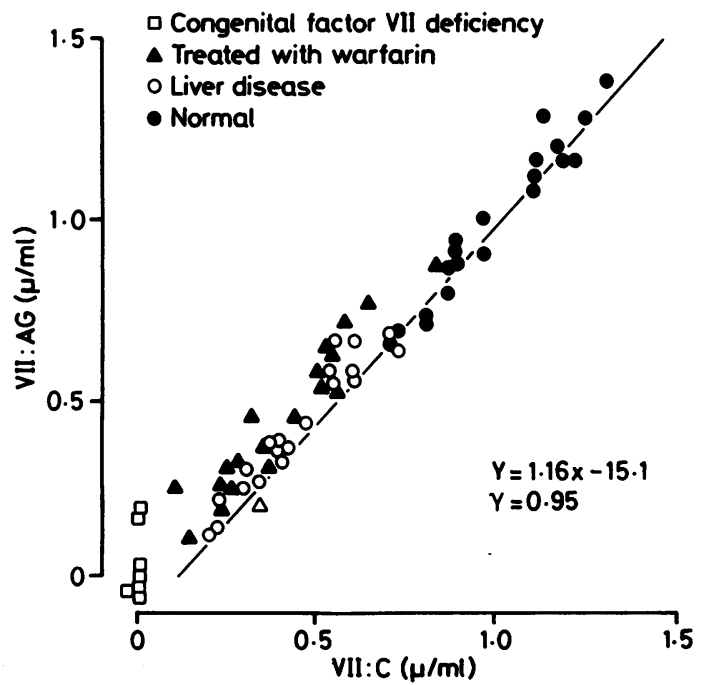

Fig 3 VII:C and VII:Ag in plasma. Correlation of VII:C concentration (using immunodepleted substrate) and VII: $\mathrm{Ag}$ concentrations (monoclonal antibody-IRMA) in 20 normal plasmas (O), 20 patients with liver disease (O), 20 treated with warfarin ( $\mathbf{\Delta})$ and seven with congenital factor $V I I$ deficiency ( $\square$ ). chromatography. The purification of VII:Ag was 159757 -fold with a recovery of $36 \%$ (table 2 ). The purified factor VII showed a single band on sodium dodecyl sulphate polyacrylamide gel electrophoresis (fig 4).

\section{Discussion}

The problems of obtaining Factor VII deficient substrate for VII:C assays are those of short supply and potential infectivity of material derived from congenitally deficient patients. The preparation of immuno-

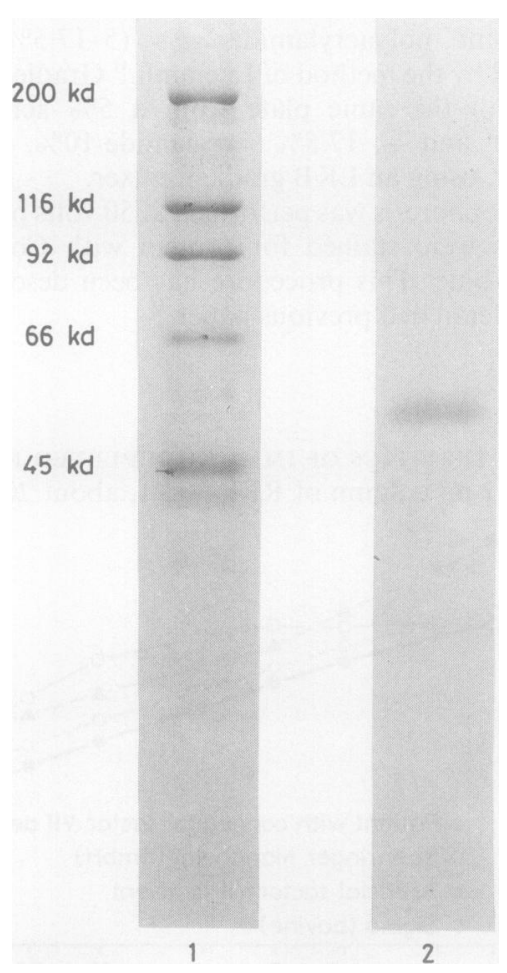

Fig 4 SDS-PAGE analysis of factor VII purified on RFFVII-1 column. Factor VII, eluted from the RFF-VII/1 column was applied to an SDS polyacrylamide gradient gel (5$17 \cdot 5 \%$ ). Lane 1: molecular weight standards (Bio-Rad high molecular weight), Lane 2: $5 \mu \mathrm{g}$ factor VII. 


\begin{tabular}{|c|c|c|c|c|c|}
\hline \multicolumn{3}{|l|}{ Total } & \multicolumn{2}{|c|}{ Purification (specific activity in $\mu / m g$ ) } & \multirow{2}{*}{$\begin{array}{l}\text { Recovery } \\
(\%)\end{array}$} \\
\hline Protein (mg) & $V I I: C(U)$ & $V I I: A g(U)$ & $\overline{V I I: C}$ & $V I I: A g$ & \\
\hline $\begin{array}{c}530 \times 10^{3} \\
11 \times 10^{3} \\
6.8 \times 10^{3} \\
95 \\
1.2\end{array}$ & $\begin{array}{l}7,000 \\
6,762 \\
4,842 \\
2,480 \\
1,560\end{array}$ & $\begin{array}{l}7,000 \\
6,891 \\
4,899 \\
2,654 \\
2,532\end{array}$ & $\begin{array}{c}1(0.013) \\
46 \cdot 5(0 \cdot 613) \\
56 \cdot 9(0 \cdot 712) \\
1,977(26 \cdot 11) \\
98,429(1300)\end{array}$ & $\begin{array}{r}1(0.013) \\
47 \cdot 4(0.625) \\
54 \cdot 5(0.720) \\
2,115(27.94) \\
159,757(2110)\end{array}$ & $\begin{array}{l}100 \\
98.4 \\
70 \cdot 0 \\
37.9 \\
36.2\end{array}$ \\
\hline
\end{tabular}

depleted plasma has been reported using a rabbit antiserum to factor VII' ${ }^{1}$ or a monoclonal antibody. ${ }^{7}$ In the present study we produced factor VII deficient plasma by high speed, immunoaffinity chromatography using the monoclonal antibody RFF-VII/1 bound to sepharose.

This biodepleted substrate (VII:C $<0.3 \mathrm{U} / \mathrm{dl}$ and VII:Ag $<0.05 \mathrm{U} / \mathrm{dl}$ ) gave an excellent standard curve over a wide range of normal plasma dilutions. There was a good correlation of VII:C concentrations with those obtained using a commercial substrate for plasma samples from 20 normal subjects, 20 patients with liver disease, 20 treated wth warfarin and seven patients with severe congenital factor VII deficiency.

By using plasma from normal healthy donors, tested for hepatits B virus and HIV, biodepleted plasma can be obtained that is free from these infectious agents, thus making the substrate safer for laboratory staff to handle. The yield of factor VII depleted plasma was very high-a $1 \mathrm{ml}$ column yielding around $200 \mathrm{ml}$ of biodepleted plasma. The contact time was minimal and the column could be regenerated with $2 \mathrm{M}$ potassium isothiocyanate (data not shown). The standard curve for VII:C concentration obtained with the biodepleted plasma was linear over a wide range of plasma dilutions. It compared well with the best available commercial substrate and was much better than either the plasma from a congenitally deficient patient or the artificial bovine substrate. The biodepleted plasma can be obtained in a reproducible manner and it is thus not subject to the deterioration on storage often associated with plasma from congenitally deficient patients.

Results for VII:C activity on all groups of patients studied were exactly comparable with those obtained using the best available commercial substrate.

Purification of factor VII from plasma has been performed previously by lengthy procedures..$^{11314}$ The yield of factor VII obtained by purification on the RFF-VII/1 column was high $(36 \%)$ and the specific activity of the protein obtained $(2110 \mathrm{U} / \mathrm{mg})$ compared well with that reported earlier. ${ }^{10}$ The purified protein gave a single $50000 \mathrm{Kd}$ band by SDS-PAGE analysis. This method of purification would be suitable for preparing factor VII for biochemical analysis and for the study of factor VII variants.
Sadhna Chand was supported by Speywood Laboratories Ltd. We thank Dr Charles Rizza for supplying us with some of the factor VII deficient plasma.

\section{References}

1 Bertina RM, Orlando M, Tiedemann-Alderkamp GHJ. Preparation of a human factor VII deficient plasma. Thromb Res 1978;13:537-41.

2 Nemerson Y, Clyne LP. An assay for coagulant factor VII using factor VII-depleted bovine plasma. J Lab Clin Med 1974;83:301-3.

3 Hemker HC, Swart ACW, Alink AJM. Artificial reagents for factor VII and factor X, a computer program for obtaining reference tables for one-stage determinations in the extrinsic system. Throm Diath Haem 1972;27:205-11.

4 Ragni MV, Lewis JH, Spero JA, Hasiba U. Factor VII deficiency. Am J Haematol 1981;10:79-88.

5 Meade TW, North WRS, Chakrabarti R, Stirling Y, Haines AP, Thompson SG. Haemostatic function and cardiovascular death: early results of a prospective study. Lancet 1980;i:1050-4.

6 Broze GJ, Hickman S, Miletich JP. Monoclonal anti-human factor VII antibodies. J Clin Invest 1985;76:937-46.

7 Cerskus AL, Ofosu FA, Birchall KJ, et al. The immunodepletion of factor VII from human plasma using a monoclonal antibody. Br J Haematol 1985;61:467-75.

8 Goodall AH, Meek FL, Waters JA, Miescher GC, Janossy G, Thomas HC. A rapid one-step radiometric assay for hepatitis B surface antigen utilising monoclonal antibodies. $J$ Immunol Methods 1982;52:167-74.

9 Takase T, Chand S, Tuddenham EGD, Goodall AH. Monoclonal antibodies to human factor VII: a one-step immunoradiometric assay for VII:Ag. J Clin Pathol 1988;41:337-341.

10 Mikami S, Tuddenham EGD. Studies on immunological assay of vitamin $\mathrm{K}$ dependent factors I. Measurement of factor VII antigen by radioimmunoassay. Br J Haematol 1986;62:171-81.

11 Laemmli UK. Cleavage of structural proteins during the assembly of the head of bacteriophage T4. Nature (Lond) 1970;227:680 5.

12 Rotblat F, O'Brien DP, O'Brien FJ, Goodall AH, Tuddenham EGD. Purification of human factor VIII:C and its characterization by Western blotting using monoclonal antibodies. Biochemistry 1985;24:4294-300.

13 Broze GJ, Majerus PW. Purification and properties of human coagulation factor VII. J Biol Chem 1980;255:1242-7.

14 Majaj SP, Rapaport SI, Brown SF. Isolation and characterization of human factor VII. J Biol Chem 1981;256:253-9.

Requests for reprints to: $\operatorname{Dr}$ A H Goodall, Haemophilia Centre, Royal Free Hospital, London NW3 2QG, England. 